\title{
Factors Related to HIV/Tuberculosis Coinfection in a Brazilian Reference Hospital
}

\author{
Bráulio Matias de Carvalho', André Jalles Monteiro² ${ }^{2}$, Roberto da Justa Pires Neto ${ }^{3}$, \\ Thalles Barbosa Grangeiro ${ }^{4}$ and Cristiane Cunha Frota ${ }^{1}$ \\ ${ }^{1}$ Laboratory of Research in Mycobacteria, Departament of Pathology and Legal Medicine; ${ }^{2}$ Department of Statistic and Mathematic; ${ }^{3}$ São José \\ Hospital of Infectious Diseases; ${ }^{4}$ Laboratory of Molecular Genetic, Department of Biology; Federal University of Ceará, Fortaleza, CE, Brazil
}

\begin{abstract}
Infection with both Human Immunodeficiency Virus (HIV) and Mycobacterium tuberculosis is currently the world's leading cause of death due to infectious agents. We evaluated factors related to the development of tuberculosis (TB) in HIV-infected patients who were being treated at an infectious diseases hospital in Fortaleza, Ceará, Brazil. From January 2004 to December 2005, we made an epidemiological study through the analysis of the medical records of 171 patients, who were diagnosed as having both HIV and tuberculosis. Among these co-infected patients, most $(81 \%, p=0.0006)$ were male. Co-infection was more frequent $(87.8 \%)$ among patients over 40 years of age and those with lower educational levels (less than eight years of schooling). Forty-one percent of the patients in the study had not had a smear culture test for acid-fast bacilli (AFB). CD4 cell counts were lower than 200 cells/ $\mu \mathrm{L}$ in $71.9 \%$ of the patients, the mean being 169 cells $/ \mu \mathrm{L}$. This type of data is important for establishing strategies to improve the control of tuberculosis in $\mathrm{HIV}$-infected patients.
\end{abstract}

Key-Words: HIV, Mycobacterium tuberculosis, HIV/TB co-infection, risk factors, AIDS.

Being infected with both Human Immunodeficiency Virus (HIV) and Mycobacterium tuberculosis is the world's leading cause of death due to infectious agents [1,2]. Approximately 13 million people are infected with both of these infectioncausing agents [3]. Pandemic HIV has increased the prevalence of tuberculosis (TB), especially in poor and developing countries [4]. The main impact has been in sub-Saharan Africa, where official reports of TB cases have tripled since the 1980's. The mortality rate has reached $20 \%$ in that region, compared to $5 \%$ in countries with good tuberculosis control programs [3]. Moreover, there is an annual increase of $10 \%$ in the number of TB cases in these African countries, mainly among individuals between 15 and 49 years old [5].

The World Health Organization (WHO) estimated that there would be 9.2 million new TB cases in 2006, resulting in 1.7 million deaths [6]. Of these cases, $7.7 \%$ would be HIV/TB co-infected. At the end of 2007, 33.2 million people were HIV positive, resulting in 2.1 million deaths [4].

In Brazil, 78,834 cases of TB were officially reported in 2006, with an incidence in 2005 of 43.8 cases per 100,000 inhabitants. The Brazilian Health Ministry has reported increasing TB incidence and an increase in the numbers of patients who did not complete the full course of antibiotic treatment from 2005 to 2006 [7]. These increases are at least in part an artifact of declining numbers of notified patients, and are also heavily influenced by policy changes in case detection, diagnosis, registration, and release from control, and therefore may be misleading [8].

In Ceará state, there was a decrease in the number of TB cases, from 44.0 per 100,000 inhabitants in 2006 to 40.0 per Received on 3 February 2008; revised 20 July 2008.

Address for correspondence: Dr. Cristiane Cunha Frota. Rua: Monsenhor Furtado SN. Rodolfo Teófilo. Zip code: 60441-750. Fortaleza-CE, Brazil. Phone: +55 0xx 85 3366.8303. Fax: +55 0xx 85 3366.2853. E-mail: ccfrota@fortalnet.com.br.

The Brazilian Journal of Infectious Diseases

2008;12(4):281-286. (C) 2008 by The Brazilian Journal of Infectious Diseases and Contexto Publishing. All rights reserved.
100,000 inhabitants in 2007. A total of 3,322 new cases were registered in 2007, of which 56\% were bacillary pulmonary tuberculosis. It is estimated that $91 \%$ of the municipalities reported cases, while the remaining $9 \%$ of the municipalities did not report or did not diagnose the cases. Among all registered new cases in 2006, 3.7\% (151 cases) were HIV/TB co-infected patients. There was also an increase in the number of cases of HIV/TB co-infection from 2005 to 2006 [7,9].

There is a much greater risk of HIV/TB co-infected patients developing active TB, either from the latent infection being reactivated or due to the rapid progression of a new infection [10-13]. The risk of developing active TB in HIV patients increases from 5 to $15 \%$ annually, due to the latent infection being reactivated; this depends on the degree of immunocompromise [12,14,15]. A study conducted among gold miners in South Africa showed that the risk of TB doubles within one year of HIV infection, but only increases slightly during the following years [5]. It has been noted that pulmonary TB occurs relatively early in the spectrum of HIV related infections and often before other AIDS-defining conditions. The increase in the risk of developing TB soon after being infected with HIV might be explained by the risk associated with seroconversion illness or of being concurrently infected with HIV and TB. For this reason, individuals infected with HIV have increased susceptibility to active tuberculosis. HIV is the main risk factor for the development of TB [10,12,16-18].

To date, there has been limited epidemiological data regarding risk factors among HIV/TB co-infected patients. Consequently, we conducted a case-control study of HIVinfected patients to determine possible risk factors that are linked to developing TB.

\section{Material and Methods}

The medical records were examined for all patients who had been confirmed to have TB at the Hospital São José de Doenças Infecciosas (HSJDI). This is a 118-bed teaching 
hospital in Northeast Brazil, a leading hospital for treating patients with infectious disease, including AIDS. On average, HSJDI cares for 2,611 HIV-positive patients per month. Patients who sought care at HSJDI at any time from January 2004 to December 2005 were eligible to participate in the study if they were at least 15 years of age and had signs, symptoms or laboratory results suggesting TB and HIV [19]. Mycobacterium tuberculosis was not confirmed by either culture or positive AFB smears in all eligible participants. This project was approved by the HSJDI Ethics Committee.

The 103 patients in the control group were randomly selected from among the HIV-positive patients who had no previous or current, confirmed or suspected history of TB, who were receiving care at HSJDI during this same period. A standardized form was used to collect data regarding age, gender, marital status, social behavior, economic status, clinical, radiological and laboratory tests. All these factors had been identified as being related to TB.

Data was recorded using EXCEL for Windows (version 2000) and transferred to SPSS (a statistics program) for analysis. The Student $t$ test was used to compare the means of continuous variables. A non-parametric test (MannWhitney test) was also used to compare data with high asymmetry. Univariate analyses of the association of clinical, laboratory and socio-demographic categorical variables were performed using the Chi-square and Fisher tests, estimating the crude odds ratios (OR) with their respective 95\% confidence intervals (CI).

\section{Results}

During the study period, 1,309 HIV cases were registered in the state of Ceará [6]. Cases of co-infected patients at HSJDI who were over 15 years of age, regardless of their HIV clinical stage, but who had confirmed cases of TB were analyzed. Some of the variables studied are shown in Table 1.

A total of 171 confirmed HIV/TB co-infected cases were reviewed, 139 of which were men $(81.3 \%, \mathrm{p}=0.0006)$ and 137 were between 27 and 49 years old (80.6\%). The age distribution was asymmetrical, with patients ranging from 16 to 78 years old. There was a predominance of TB cases among single patients, $73.7 \%(\mathrm{p}=0.0265)$.

The educational level of 146 patients, as well as household size (number of adults) and income were included in the study. Educational level is traditionally used as an indicator of socioeconomic level. Patients with a lower educational level had a higher risk of developing TB (87.9\%, $\mathrm{p}<0.0001$, relative risk $=2.3633$ ). A similar trend was found for patients with low incomes; TB was more common among individuals earning the monthly minimum wage of U\$94.00 or less $(70.9 \%, \mathrm{p}=$ 0.6005). However, low income was not a significant risk factor for developing TB (relative risk $=1.0506$ ). Among hostrelated factors, TB was not associated with smoking or with drinking alcohol. These habits were actually more frequent among patients without $\mathrm{TB}(\mathrm{p}=0.068$ and $\mathrm{p}=0.034$, respectively). The risk of $\mathrm{TB}$ did not significantly increase with a reported family history of $\mathrm{TB}$, independent of the kind of contact $(\mathrm{p}=0.0992)$.

The site of TB infection, as well as acid-fast stain, L-J culture and skin test results, are shown in Table 2. Among the $171 \mathrm{HIV} / \mathrm{TB}$ patients, only 96 (56.14\%) had been submitted to acid-fast stain and L-J culture tests. Only 18 of these 96 patients were positive in both the acid-fast stain and culture tests, while 13 were acid-fast stain positive and culture negative, and 18 were acid-fast stain negative and culture positive.

Immunocompromise was significantly more common in TB patients, compared to those without TB ( $\mathrm{p}<0.0001)$. CD4 cell counts of under 200 cells/ $\mu \mathrm{L}$ were observed in 110 (71.9\%) of the HIV/TB coinfected patients. The percentage of nonreactive PPD (Protein Purified Derived) was higher $(\mathrm{p}=0.0407$ ) among patients with AIDS (84.5\%) compared to those without AIDS (40.0\%). Since only a small number of patients took the PPD test, it was not possible to compare the tests to the TB clinical presentations.

It was observed that PPD test results were not significantly correlated with the CD4 count $(n=73, p=0.7587$, Figure 1$)$. Also, no specific clinical form of TB was significantly associated with the CD4 count ( $\mathrm{p}=0.2120$, Figure 2$)$.

\section{Discussion}

We investigated the factors influencing active TB in HIVinfected patients by analyzing control HIV patients who did not have TB. Most patients with HIV/TB co-infection had not been exposed to TB carriers previously. We suggest that active $\mathrm{TB}$ is a result of either fast primary progression of a recent infection or reactivation of a latent infection, a conclusion also reached by Ho [20].

Gender (in this case, male), advanced age, not being married and low educational levels were all positively correlated with the risk of developing active TB. Kerr-Pontes et al. [21] and Henn [22] also reported that (male) gender is a high risk factor for developing active TB. In addition, there are more men with registered cases of TB without $\mathrm{HIV}$, at a ratio of 2:1 men to women [23]. It is not known whether the predominance in males is due to the lack of official records for women, due to differences in social behavior or to poor health public services, or a combination of both. However, Bellamy et al. [24] suggests that there is a relationship between TB susceptibility and chromosome $\mathrm{X}$.

The HIV/TB-infected patients were most abundant in the 41 to 45 year old group. Previous studies demonstrated predominance in young adults averaging 33 years of age $[12,21,25,26]$. The results in our study reflect the prolonged survival of HIV patients, since the average age of those with registered cases of AIDS in Brazil between 2002 and 2005 was 35.4. [7]. The predominance of TB among single people is also a reflection of socio-economic status, especially among men, who frequently migrate while searching for better jobs, and are in contact with more people, thus increasing the probability of exposure to the bacilli. 
Table 1. Regression analysis of possible risk factors for tuberculosis (TB) in HIV/TB coinfected patients.

\begin{tabular}{|c|c|c|c|c|c|c|c|}
\hline & \multicolumn{2}{|c|}{ HIV } & \multicolumn{2}{|c|}{ HIV + TB } & \multirow[t]{2}{*}{ p-value } & \multirow[t]{2}{*}{ RR } & \multirow[t]{2}{*}{$\begin{array}{l}\text { Odds ratio } \\
\text { (95\% CI) }\end{array}$} \\
\hline & $\mathbf{N}$ & $\%$ & $\mathbf{N}$ & $\%$ & & & \\
\hline Total (n) & 103 & & 171 & & & & \\
\hline \multicolumn{8}{|l|}{ Sex } \\
\hline Male & 64 & 31.53 & 139 & 68.47 & 0.0006 & 1.5192 & 2.6470 \\
\hline Female & 39 & 54.93 & 32 & 45.07 & & & $(4.0962,15.0599)$ \\
\hline Age (mean) & 36 & \pm 10.61 & 41 & \pm 10.93 & 0.0001 & & \\
\hline \multicolumn{8}{|l|}{ Marital status } \\
\hline Single & 60 & 32.26 & 126 & 67.74 & 0.0265 & 1.2742 & 1.8500 \\
\hline Others & 37 & 46.84 & 42 & 53.16 & & & $(1.0799,3.1693)$ \\
\hline \multicolumn{8}{|l|}{ Schooling } \\
\hline$<8$ years & 36 & 19.89 & 145 & 80.11 & $<0.0001$ & 2.3633 & 7.8542 \\
\hline$>8$ years & 39 & 66.10 & 20 & 33.90 & & & $(4.0962,15.0599)$ \\
\hline \multicolumn{8}{|l|}{ Income } \\
\hline$<1 \mathrm{MW}^{\mathrm{a}}$ & 34 & 23.29 & 112 & 76.71 & 0.6005 & 1.0506 & 1.2174 \\
\hline >1 MW & 17 & 26.98 & 46 & 73.02 & & & $(0.6193,2.393)$ \\
\hline \multicolumn{8}{|l|}{$\mathrm{HH}^{\mathrm{b}}$ contacts } \\
\hline Yes & 3 & 21.43 & 11 & 78.57 & 0.0992 & 1.4311 & 3,0119 \\
\hline No & 69 & 45.10 & 84 & 54.90 & & & $(0.808,11.2269)$ \\
\hline \multicolumn{8}{|l|}{ Smoking } \\
\hline Yes & 36 & 43.37 & 47 & 56.63 & 0.0680 & 0.8206 & 0.5864 \\
\hline No & 53 & 30.99 & 118 & 69.01 & & $(0.3411,1.008)$ & \\
\hline \multicolumn{8}{|l|}{ Alcohol } \\
\hline Yes & 51 & 44.74 & 63 & 55.26 & 0.0034 & 0.7531 & 0.4481 \\
\hline No & 37 & 26.62 & 102 & 73.38 & & $(0.2645,0.7591)$ & \\
\hline $\begin{array}{l}\text { CD4 cells } \\
\text { count (mean) }\end{array}$ & 377 & \pm 269 & 169 & \pm 119 & $<0.0001$ & & \\
\hline $\begin{array}{l}\text { Number of adults } \\
\text { in HH (mean) }\end{array}$ & 3.4 & \pm 2.398 & 3.0 & \pm 1.705 & 0.2349 & & \\
\hline \multicolumn{8}{|l|}{ HAART $^{\mathrm{c}}$} \\
\hline Yes & 57 & 55.34 & 153 & 89.47 & 2.5905 & 6.8596 & 0.0000 \\
\hline No & 46 & 44.66 & 18 & 10.53 & & & $(4.0962,15.0599)$ \\
\hline
\end{tabular}

$\mathrm{RR}=$ rate ratio; $\mathrm{CI}=$ confidence interval; ${ }^{\mathrm{a}} \mathrm{MW}=$ monthly minimum wage (USD\$94.00); ${ }^{\mathrm{b}} \mathrm{HH}=$ household; ${ }^{\mathrm{H}} \mathrm{HART}=$ highly active antiretroviral therapy.

Educational level can affect the behavior of HIV patients and an understanding of education level can help target interventions in order to prevent infection. There was no significant association between educational level and drinking or smoking. Most of the HIV/TB co-infected patients had less than eight years of schooling and also had low incomes. This apparent association might be a consequence of other health hazards, including the lack of health education and not having access to health care.

Several studies have demonstrated the impact of highly active antiretroviral therapy (HAART) on HIV-infected patients; these treatments have been successful in restoring immune function and reducing morbidity and mortality $[10,27,28,29,30,31]$. The use of antiretroviral therapy (ART) in these patients reduces the risk of developing active TB [32,33,34], being associated in HIV-infected TB patients with higher rates of survival, when used during and after TB treatment $[25,27,35]$. We also found that ART reduces the risk of developing active TB in HIV-patients. However, there were certain limitations in our study concerning ART. The time of initiation of ART was not recorded, nor were analyses made of the safety, adhesion and efficacy of the regimen for the patients. For a number of patients, the result of treatment or cause of death could not be defined, either because the patients did not return to the hospital or due to the fact that they passed away outside the hospital. In addition, the appropriate management of HIV-associated TB is complicated by drug-drug interactions, overlapping toxicities, immune reconstitution syndrome, and pill burden [10,36]. Nowadays, WHO recommends that HIV-infected TB patients eligible for ART begin treatment within two weeks to two months after the beginning of anti-TB treatment [37].

Most of our patients with HIV/TB co-infection presented very low CD4 cell counts. Most CD4 cell counts were 
Table 2. Distribution of tuberculosis cases according to site, skin test reaction and microbiological analysis (Lowestein-Jensen culture and Acid-Fast stain).

\begin{tabular}{lccc}
\hline & Total & N & \% \\
\hline Site & 38 & & \\
$\quad$ Pulmonary & & 18 & 47.37 \\
$\quad$ Extrapulmonary & & 16 & 42.11 \\
$\quad$ Disseminated & 171 & 15 & \\
Skin Test & & 62 & 8.77 \\
$\quad$ Reactive & & 94 & 36.26 \\
$\quad$ Non-reactive & & & 54.97 \\
$\quad$ Not Done & 96 & 18 & \\
Microbiologic Analysis & & 18 & 18.75 \\
Culture positive & & 13 & 18.75 \\
$\quad$ Acid-Fast stain positive & & 47 & 13.54 \\
$\quad$ Acid-Fast stain negative & & & 48.96 \\
Culture negative & &
\end{tabular}

Figure 1. Relation between CD4+ lymphocyte count (cells/ $\mu \mathrm{L}$ ) and PPD skin test. The symbol $\bullet$ represents extreme values. Reaction to PPD was considered positive when equal or greater than $5 \mathrm{~mm}$.

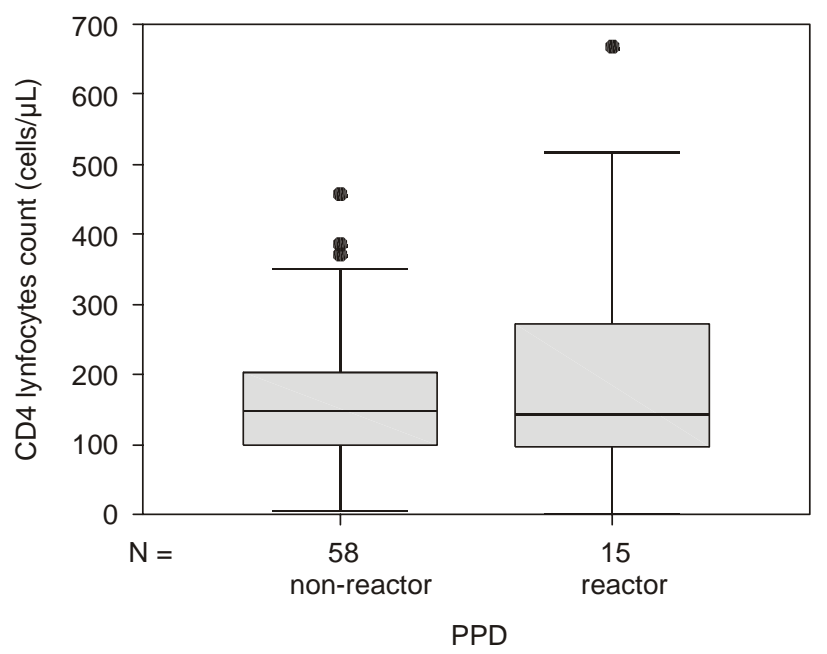

determined while the patients were at the HIV hospital, at the time of HIV diagnosis. HIV/TB co-infection reflects the synergy of these diseases, as $M$. tuberculosis infection increases the HIV viral load, which consequently induces host immunosuppression and the virulence of the bacilli. HIVinduced immunosuppression increases the likelihood that quiescent $M$. tuberculosis will reactivate. TB up-modulates the host immune system; a T-cell that is activated in response to infection from M. tuberculosis produces more HIV than a quiescent cell; HIV expression increases in the face of coinfections. The high HIV viral load increases the rate of disease progression, which in turn increases HIV infectiousness [11].
Figure 2. Relation between CD4+ lymphocyte count (cells/ $\mu \mathrm{L}$ ) and clinical presentation according to the site of the infection. The symbol $\bullet$ represents extreme values and represents outliers.

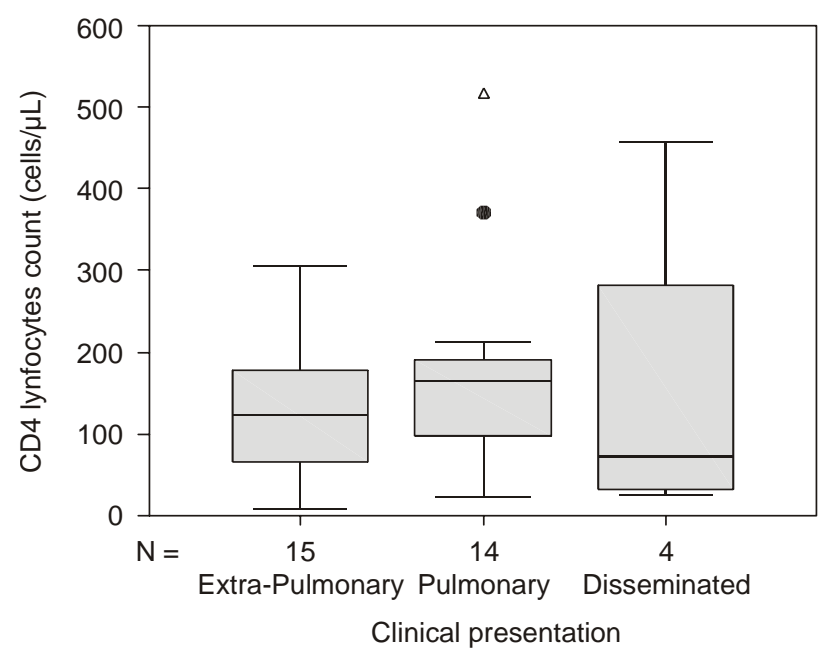

The clinical and radiological presentation of TB in HIVinfected patients with CD4 cell counts above $350 \mathrm{cell} / \mathrm{mm}^{3}$ is similar to that seen in individuals who are not infected with HIV [38-40]. In patients with low CD4 counts, TB can have an atypical presentation, with extrapulmonary involvement or disseminated infection. Approximately half of our patients presented either extrapulmonary TB or disseminated TB. This is a consequence of the high degree of immunosuppression in such patients, as discussed above. In these patients, HIVinduced impairment of cellular immunity allows the development of pulmonary infiltrates in any region of the lung; typically these are without cavitations but are accompanied 
by intrathoracic lymph node enlargement [40]. Kerr-Pontes et al. [21] observed an incidence of extrapulmonary TB of 23.9\% in the same state; however, they did not evaluate the level of immunocompromise.

We also evaluated the importance of sputum AFB smears and sputum cultures as basic TB diagnostic tools. However, sputum smears of HIV/TB co-infected patients are more likely to be low grade positive or negative. Consequently, it is difficult to diagnose extrapulmonary or disseminated TB, especially when it involve deep sites that are difficult to reach to collect samples [38]. In addition, these patients are thought to be less efficient at transmitting TB infection, since they have less lung cavitation [41]. Although the use of sputum cultures should be encouraged to assist in the diagnosis of HIV-related TB, 41\% of our patients had not had sputum cultures; Kerr-Pontes et al. [21] found that $54 \%$ of their patients also had not been submitted to this procedure. Though there was a slight reduction in the number of HIV patients that were not tested by sputum culture, it is important to perform this test in order to improve TB diagnosis. More rapid and simple culture methods are needed in order to expand and decentralize their use. Tuberculosis screening also offers the opportunity to provide treatment of latent tuberculosis infection (prevention therapy) for people living with HIV, when active TB has already been excluded [42].

In conclusion, various factors, such as gender, age, marital status, low CD4 cell counts and the use of ART can influence TB in HIV patients. The acid-fast stain and culture examinations should be considered together to assess active TB in HIV patients. Interaction between HIV and TB treatment and prevention programs will lead to more effective treatment and control of TB among HIV patients.

\section{Acknowledgements}

We thank the patients who participated in our study and the staff at Hospital São José de Doenças Infecciosas for their collaboration.

\section{References}

1. Weiss R.A., McMichael A.J. Social and environmental risk factors in the emergence of infectious diseases. Nat Med 2004;10(12):S70-6.

2. Friedland G., Churchyard, G.J., Nardell E. Tuberculosis and HIV Coinfection: Current State of Knowledge and Research Priorities. J Infect Dis 2007;196(1):S1-S3.

3. Nunn P., Williams B., Floyd K., et al. Tuberculosis control in the era of HIV. Nat Rev Immunol 2005;5:819-26.

4. UNAIDS. AIDS epidemic update: December 2007. WHO Library Cataloguing-in-Publication Data 2007.

5. Sonnenberg P., Glynn J.R., Fielding K., et al. How soon after infection with HIV does the risk of tuberculosis start to increase? A retrospective cohort study in South African gold miners. J Infect Dis 2005;191:150-8.

6. WHO Report 2008. Global tuberculosis control - surveillance, planning, financing. Geneva, World Health Organization (WHO/ HTM/TB/2007 376) 2008.

7. Ministerio da Saude-Brasil. Indicadores e Dados Básicos - Brasil 2008. DATASUS http://w3.datasus.gov.br/datasus/datasus.php; 2008.

8. Nadol P., Stinson K.W., Coggin W., et al. Electronic tuberculosis surveillance systems: a tool for managing today's TB programs. Int J Tuberc Lung Dis 2008;12(3):8-16.
9. Secretaria de Saúde do Estado do Ceará. Informe Epidemiológico: Tuberculose. Coordenadoria em políticas em saúde http:// www.saude.ce.gov.br/internet/; 2008.

10. Goldfeld A., Ellner J.J. Pathogenesis and management of HIV/TB co-infection in Ásia. Tuberculosis 2007;87:S26-S30.

11. Vermund S.H., Yamamoto N. Co-infection with human immunodeficiency virus and tuberculosis in Asia. Tuberculosis 2007;87:S18-S25.

12. Albalak R., O’Brein R.J., Kamemerer S. et al. Trends in Tuberculosis/ Human Immunodeficiency Virus Comorbidity, United States, 1993-2004. Arch Inter Med 2007;167(22):2443-52.

13. Carvalho A.C.C., DeRiemer K., Nunes Z.B., et al. Transmission of Mycobacterium tuberculosis to Contacts of HIV-infected Tuberculosis Patients. Am J Respir Crit Care Med 2001;164:2166-71.

14. Young D.B., Perkins M.D., Duncan K., et al. Confronting the scientific obstacles to global control of tuberculosis. J Clin Invest 2008; 118 :1255-65.

15. Mendelson M. Diagnosing tuberculosis in HIV-infected patients: challenges and future prospects. Br Med Bull 2007;81-82:149-65.

16. Lazarus J.V., Olsen M., Ditiu L., et al. Tuberculosis-HIV coinfection: policy and epidemiology in 25 countries in the WHO European region. HIV Med 2008; Published article online:10Apr-2008.

17. Asten L.V., Langendam M., Zangerle R., et al. Tuberculosis risk varies with the duration of HIV infection: a prospective study of European drug users with known date of HIV seroconversion. AIDS 2003;17:1201-8.

18. Matos D.E., Lemos A.C.M., Bittencourt C., et al. Prevalence of HIV infection in patients hospitalized for tuberculosis in Bahia, Brazil. Braz J Infect Dis 2007;11(2):208-11.

19. Ministerio da Saude-Brasil. Criterios de definição de casos de aids em adultos e criancas. Secretaria de Vigilancia em Saude Programa Nacional de DST e Aids 2003.

20. Ho J.L. Co-Infection with HIV and Mycobacterium tuberculosis: Immunologic Interactions, Disease Progression, and Survival. Mem Inst Oswaldo Cruz 1996;91(3):385-7.

21. Kerr-Pontes L.R.S., Oliveira F.A.S., Freire C.A.M. Tuberculose associada à AIDS: situação de região do Nordeste brasileiro. Rev. Saúde Pública 1997;31(4):323-9.

22. Henn L., Nagel F., Dal Pizzol F. Comparison between Human Immunodeficiency Virus Positive and Negative Patients with Tuberculosis in Southern Brazil. Mem Inst Oswaldo Cruz 1999;94(3):377-81.

23. Holmes C.B., Hausler H., Nunn P. A review of sex differences in the epidemiology of tuberculosis. Int J Tuberc Lung Dis 1998;2(2):96-104.

24. Bellamy R., Beyers N., McAdam K.P.W.J., et al. Genetic susceptibility to tuberculosis in Africans: A genome-wide scan. Proc. Natl Acad Sci USA 2000;97(14):8005-9.

25. Sanguanwongse N., Cain K.P., Suriya, P., et al. Antiretroviral therapy for HIV-infected tuberculosis patients saves lives but needs to be used more frequently in Thailand. $\mathrm{J}$ Acquir Immune Defic Syndr 2008;48(2):81-9.

26. Eyob G., Guebrexabher H., Lemma E., et al. Drug susceptibility of Mycobacterium tuberculosis in HIV-infected and -uninfected Ethiopians and its impact on outcome after 24 months of followup. Int J Tuberc Lung Dis 2004;8(11):1388-91.

27. Akksilp S., Karnkawinpong, P., Wattanaamornkiat W., et al. Antiretroviral therapy during tuberculosis treatment and marked reduction in death rate of HIV-infected patients, Thailand Emerging Infectious Diseases 2007;13(7):1001-7.

28. Harries A.D. Safety, effectiveness, and outcomes of concomitant use of highly active antiretroviral therapy with drugs for tuberculosis in resource poor settings. Lancet 2006;367:944-5.

29. Mocroft A., Ledergerber B., Katlama C., et al. Decline in the AIDS and death rates in the Euro-SIDA study: an observational study. Lancet 2003;362:22-9. 
30. Dean G.L., Edwards S.G., Ives N.J., et al. Treatment of tuberculosis in HIV-infected persons in the era of highly active antiretroviral therapy. AIDS 2002;16:75-83.

31. CASCADE collaboration. Survival after introduction of HAART in people with known duration of HIV-1 infection. Lancet 2000;355:1158-9.

32. Girardi E., Antonucci G., The GISTA-SIMIT Study Group, et al. Tuberculosis in HIV-infected persons in the context of wide availability of highly active antiretroviral therapy. Eur Respir J 2004;24:11-7.

33. Williams B.G., Dye C. Antiretroviral Drugs for Tuberculosis Control in the Era of HIV/AIDS. Science 2003;301:1535-7.

34. Jones J.L., Hanson D.L., Dworkin M.S., DeCock K.M., The Adult/ Adolescent Spectrum of HIV Disease Group. HIV-associated tuberculosis in the era of highly active antiretroviral therapy. Int J Tuberc Lung Dis 2000;4(11):1026-31.

35. Breen R.A., Miller R.F., Gorsuch T., et al. Virological response to highly active anti-retroviral therapy is unaffected by anti-tuberculosis therapy. J Infect Dis 2006;193:1437-40.
36. McIlleron, H., Meintjes, G, Burman, W.J. Complications of antiretroviral therapy in patients with tuberculosis: drug interactions, toxicity, and immune reconstitution inflammatory syndrome. J Infect Dis 2007;196(1):S63-S75.

37. Harries A., Maher D., Graham S. TB/HIV: A Clinical Manual. 2nd ed. 2004; Geneva, Switzerland: World Health Organization.

38. Sharma S.K., Mohan A. Extrapulmonary tuberculosis. Indian J Med Res 2004;120:316-53.

39. Sharma S.K., Mohan A., Kadhiravan T. HIV-TB co-infection: Epidemiology, diagnosis \& management. Indian J Med Res 2005;121:550-67.

40. Picon P.D., Caramori M.L.A., Bassanesi S.L., et al. Differences in the clinical and radiological presentation of intrathoracic tuberculosis in the presence or absence of HIV infection. J Bras Pneumol 2007;33(4):429-436.

41. Narain J.P., Lo Y.R. Epidemiology of HIV-TB in Asia. Indian J Med Res 2004;120:277-8.

42. Reid A., Scano F., Getahun H., et al. Towards universal access to HIV prevention, treatment, care, and support: the role of tuberculosis/ HIX collaboration. Lancet Infect Dis 2006;6(8):483-95. 